Gut, 1988, 29, 534-536

Case report

\title{
Perforation of gastric squamous carcinoma metachronous to laryngeal carcinoma: metastatic in origin?
}

\author{
G F WHALEN, W K J HUIZINGA, AND A MARSZALEK \\ From the Dept of Surgery and Dept of Pathology, University of Natal Medical School, Durban, South Africa
}

SUMmARY The local and regional spread of squamous cancer of the head and neck is well described. We report a possible unusual pattern of spread from a primary laryngeal carcinoma, which presented as gastric perforation

\section{Case report}

A 55 year old African man (CM) presented in May 1984 with hoarseness of voice and a cough of one months duration. He had no other symptoms and had been in good health although he was a heavy smoker. His alcohol intake was moderate.

Examination revealed a tumour of the right vocal cord which involved the ventricle and anterior commissure. It appeared to extend into the subglottis and the right vocal cord was fixed. There was no cervical lymphadenopathy and no evidence of distant spread (T3NoMo). Biopsy showed a moderately differentiated squamous carcinoma.

The patient refused any treatment and was lost to follow up until March 1985 when he returned with stridor. There was still no cervical lymphadenopathy.

He underwent emergency total laryngectomy and although the tumour was invading the tissue outside the thyroid cartilage, the margins of resection were clear and there was no evidence of any lymph node involvement. Postoperatively, he received a course of radiotherapy ( 2500 rads), Bleomycin $30 \mathrm{mg}$ iv each third week in a total of four doses and methotrexate $500 \mathrm{mg}$ iv weekly in a total of four doses.

He did well until January 1986 when he came to the hospital with generalised peritonitis. At laparotomy

Address for correspondence: Mr W K J Huizinga, FRCS(Ed), Department of Surgery. University of Natal Medical School. PO Box 17039, Congella. 4013 South Africa.

Received for publication 9 November, 1987 he was found to have what appeared to be a benign gastric ulcer at the anterior aspect of the antrum near the lesser curve, which had perforated. There was no evidence of malignant disease in the abdomen and the chest radiograph appeared clear on admission. He underwent a Billroth I partial gastrectomy and recovered uneventfully.

Pathological examination of the resected gastric specimen revealed ulcerating moderately differentiated squamous cell carcinoma with keratin pearl formation (Fig. 1). In some areas tumour infiltrated the whole thickness of the gastric wall and focal vascular (venous) invasion was demonstrated (Fig. 2 ). The adjacent multiple lymph nodes and margins of excision were free of tumour.

He has been seen in follow up and continues to do well without evidence of further recurrence after six months.

\section{Discussion}

The tendency for cancer of the upper respiratory and digestive tract to occur at multiple sites is well known, and usually explained as the field effect of a particular carcinogen on a common squamous epithelium. The incidence of second primaries has been estimated to be as high as $20 \%$. Most of these are bronchogenic cancers..$^{1-3}$ Gastric epithelium is different and is also presumably susceptible to a different range of carcinogens. Although primary squamous carcinoma of the stomach does occur, ${ }^{45}$ it accounts for less than $0.7 \%$ of all primary gastric tumours, ${ }^{6}$ and therefore 


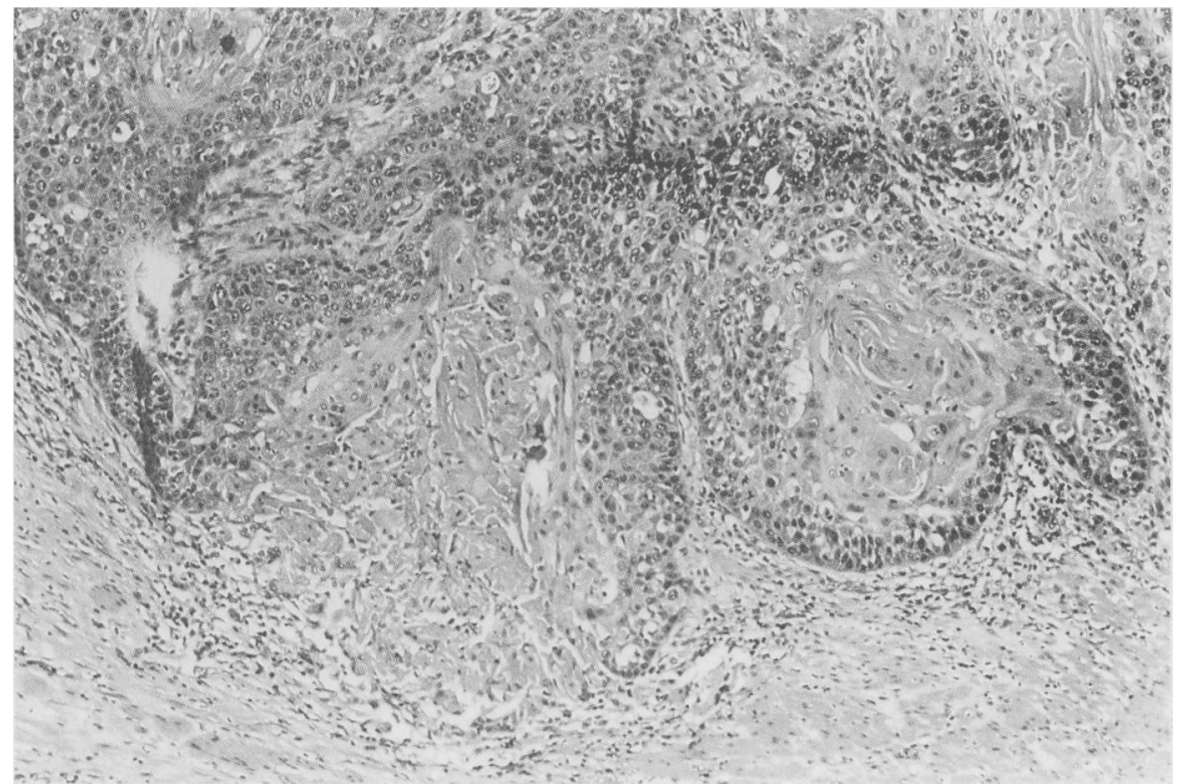

Fig. 1 Keratin pearl formation by squamous carcinoma of the stomach.

the possibility that this patient's gastric tumour represents another primary instead of a metastasis seems very remote.

Discrete metastases to the stomach are also distinctly unusual and, when they do happen, fre- quently occur in the setting of widespread metastatic disease. The tumours that metastasise to the stomach most commonly are lung and breast, reflecting their prevalence in the general population, and melanoma, which appears to have a predilection for

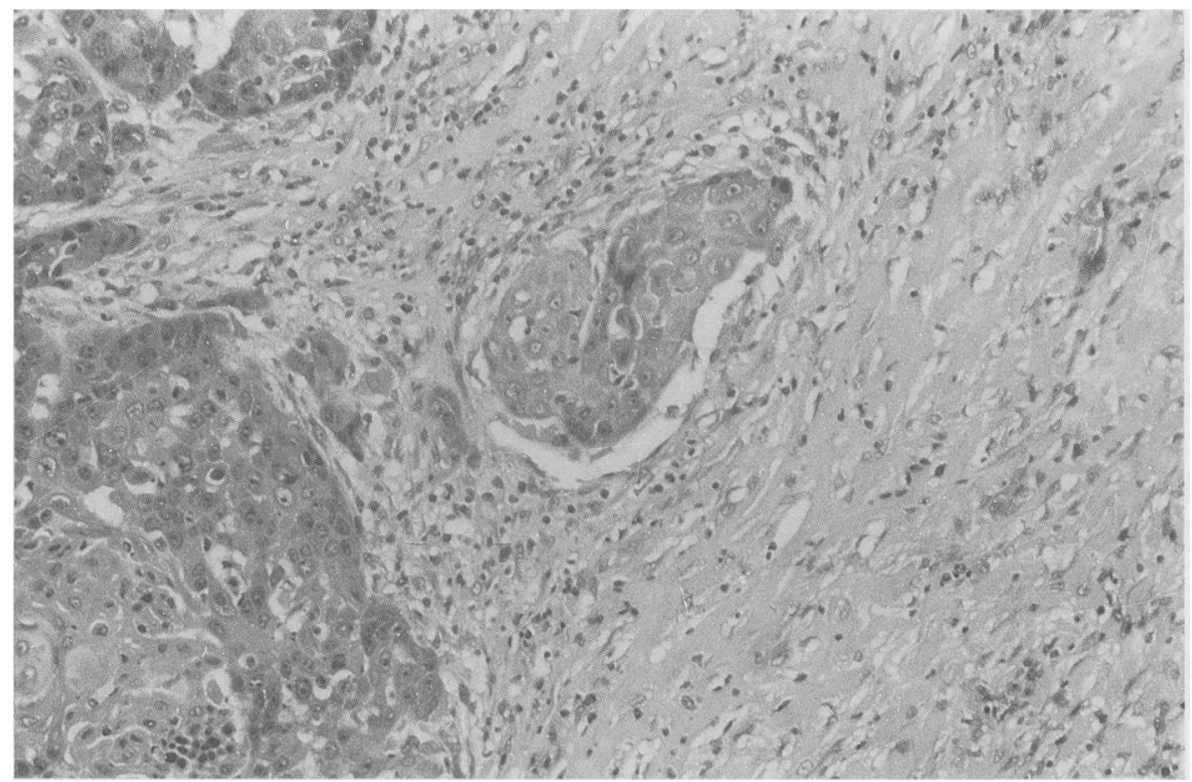

Fig. 2 Vascular (venous) invasion by squamous carcinoma of the stomach. 
the gastrointestinal tract. ${ }^{78}$ There are reports of haematemesis caused by metastatic lung cancer in the stomach' and even a report of a gastric perforation caused by poorly differentiated squamous carcinoma which was considered metastatic to a primary squamous cell carcinoma of the lung occurring at the same time. ${ }^{10}$

It is interesting to speculate on the mode of spread from the larynx to the stomach in our patient several months after total laryngectomy. Lymphatic dissemination seems an unlikely explanation in the absence of perigastric nodal disease. Haematogenous spread is probably the most likely and conventionally accepted explanation, even though the stomach is an unusual site for isolated metastases. Malignant cells in the blood are known to embolise selectively into damaged tissues." Perhaps a pre-existing gastric ulcer or erosion provided a suitable local environment?

Local implantation of tumour cells is a common technical concern of all surgeons which has been addressed most extensively in colorectal surgery. ${ }^{12}$ Implantation is a well known mode of tumour spread in the pleural and peritoneal cavities. More recently, however, it has been usually discredited as an explanation of intraluminal spread along the digestive tract.

Nevertheless, in this particular instance, where multifocal primaries cannot be invoked, and where any cogent explanation of the facts relies on the intersection of rare events, intraluminal implantation in an area of damaged gastric epithelium remains an intriguing possibility.

\section{References}

1 Cohn AM, Peppard SB. Multiple primary tumours of the head and neck. Am J Otolaryngol 1980; 1: 411-7.

2 Derrick JH, Wagenfelf AR, Harwood DP, et al. Second primary respiratory tract malignancies in glottic carcinoma. Cancer 1980; 46: 1883-6.

3 Vrabec Donald P. Multiple malignancies of the upper aerodigestive system. Ann Otol Rhinol Laryngol 1979; 88: 846-54.

4 Altshuler JH, Shaka JA. Squamous carcinoma of the stomach. Review of literature and report of a case. Cancer 1966; 16: 831-8.

5 Boswell JT, Helwig EB. Squamous cell carcinoma and adenoacanthoma of the stomach. A clinicopathological study. Cancer 1965; 18: 181-92.

6 Holland JF, Frei E. In: Cancer medicine. Philadelphia: Lea and Febiger, 1973: 1537.

7 Menuck LS, Amberg JR. Metastatic disease involving the stomach. Am J Dig Dis 1975; 20: 903-13.

8 Willis RA. The spread of tumours in the human body. 3rd ed. London: Butterworth, 1973: 216.

9 Edwards R, Royle G. Metastatic carcinoma causing haematemesis. Br Med J 1975; 2: 598-9.

10 Fletcher MS. Gastric perforation secondary to metastatic carcinoma of the lung: a case report. Cancer 1980; 46: $1879-82$.

11 Fisher B, Fisher ER, Feduska N. Trauma and the localisation of tumour cells. Cancer 1967; 20: 23-30.

12 Devita V, Hellman S, Rossenberg S. Cancer: principles and practice of oncology. Philadelphia: J Lippincott Company, 1982: 654. 